\title{
ADHESIVE BOND OF CARBON STEEL S235J0: EFFECTS OF ALUMINIUM AND POLYMER POWDER FILLED EPOXY ADHESIVES ON MECHANICAL PROPERTIES
}

\author{
Miroslav Müller' ${ }^{1}$ Petr Valášek ${ }^{2}$ \\ 1 Faculty of Engineering, Czech University of Life Science Prague, 16521 Prague, Czech Republic, e-mail: \\ muller@tf.czu.cz \\ 2 Faculty of Engineering, Czech University of Life Science Prague, 16521 Prague, Czech Republic, e-mail: \\ valasekp@tf.czu.cz
}

Received: 2016.06 .04 Accepted: 2016.07.05 Published: 2016.09.01

\begin{abstract}
The paper deals with the testing of composite materials based on aluminium and polymer microparticles. The aim of the research was to determine an influence of a content of a microparticle filler on mechanical properties of the polymer particle composite and adhesive bonds (material structural carbon steel S235J0). A preparation of adhesive bonds and a process of testing of the adhesive bonds were in accordance with the standard CSN EN 1465. The adhesive bond strength was increased when adding the aluminium and polymer powder filler. The adhesive bond strength increase was the highest at the adhesive bond with the adhesive in the form of the composite (15 $\mathrm{g}$ of the filler : $100 \mathrm{~g}$ of the matrix). The adhesive bond strength increase was $14.3 \%$ $(13.68 \pm 0.43 \mathrm{MPa})$. Adhesive bonds evinced an adhesive type of a fracture surface. By adding the filler in a form of microparticles there was a change of the failure type on adhesive-cohesive and a cohesive type. Fracture surfaces and an adhesive bond cut was examined with SEM (scanning electron microscopy) using a microscope MIRA 3 TESCAN.
\end{abstract}

Keywords: adhesive bond strength, SEM, microparticles filler, tensile strength, elongation, structural two-component epoxy.

\section{INTRODUCTION}

An adhesive bonding technology is a prospective bonding technology of diverse materials [1, 2]. The adhesive bond is a complex of three layers - an adhesive bonded material (called adherent), an adhesive layer and a cohesive layer [3, 4]. A requirement for a mass decreasing of the construction is put when designing constructions [5, 6]. The use of the adhesive bonding technology in the construction of transport means and agricultural machines secures a stiffness comparable with mechanical fasteners or spot-welds. Further, the adhesive bonding technology increases an energy absorption reducing a noise and vibrations $[5,6]$. The adhesive bonding technology advan- tage is a possibility to introduce an automation in the production process [1]. However, the adhesive bonding technology has also its disadvantages, e.g. the strength of the bond depends on a choice of the adhesive, an overlapping geometry, a service life of the bond is limited etc. These properties can significantly influenced the final bond $[5,7]$.

In the area of the bonding of sheets of metals single-lap adhesive bonds are used. Technologies such as an adhesive bonding, a riveting and a welding are particularly used in manufacturing corporations focused on bonding of the metal sheets. These methods are frequently combined [6].

Epoxies are widely used as high-performance structural adhesives $[8,9,10,11,12]$. Epoxy 
resins are attractive for metal-bonding adhesive systems. Epoxies are able to bond well a variety of treated or untreated metal surfaces $[13,14,15]$. Structural two-component epoxies are important matrix materials for forming of advanced composites. The reinforcing materials in advanced composites take many forms. A number of studies in particle composites have been undertaken with microparticles [16].

The filler of composite materials is different: $\mathrm{Al}_{2} \mathrm{O}_{3}, \mathrm{SiC}$, glass beads, minerals, various metals, rubber particles. Mechanical properties of polymer composites strongly depend on the particle size $[17,18]$. The type and the size of the filler depend on an application of the composite. A mild increase of the adhesive bond strength can occur by adding the filler [16]. A filler can be added into the layer of the adhesive [13]. A price of the adhesive is decreased and a substantial change in mechanical properties can be achieved by adding an optimum volume of a filler i.e. a reinforcement. A composite material is created by this way. Composite materials are promising structural components $[9,18,19,20]$. They comprise one or more discrete phases stored in the continuous phase $[8,9]$.

A promising result was obtained through an experimental investigation that the epoxy adhesive retains its adhesion strength even with as much as $50 \mathrm{wt} . \%$ addition of the aluminium filler [13]. The effect of the particle fillers on the behaviour of the matrix is very diverse [22]. It depends on their specific properties and on the combination with the properties of the matrix. That is why it is important to take into regard the matrix properties, the particle sizes, the concentration and mutual cohesiveness of the filler and the matrix when designing the product containing the particle filler composite $[1,8,9,23]$. The aim of the research was to determine the influence of the content of the microparticle filler on the mechanical properties of the polymer particle composite and the adhesive bond of the bonded material in the form of the structural carbon steel S235J0.

\section{MATERIAL AND METHOD}

This paper presents the laboratory experiment results performed on the structural carbon steel S235J0 with the polymer composites reinforced with the aluminium microparticles (a multi-plate shape) and the plastics (a spherical shape). The objective of this study was to develop an influence of the aluminium and plastic filler content on the mechanical properties of the adhesive bonds bonded by the two-component epoxy ChS Epoxy 1200 (hardener P11 - Diethylentriamin). A mixture of the adhesive was prepared by mixing of a part A (a resin) and a part B (a hardener) in a given ratio. The filler was added in the required ratio after mixing parts A (epoxy resin) and B (hardened P11 based on Diethylentriamin). The determination of the concentration of the sub-components was expressed using a weight relative to $100 \mathrm{~g}$ of the matrix (the two-component adhesive).

The filler was added into the matrix ChS Epoxy 1200 (two-component reactoplastics resin) in the ratio of $1,2,5,10,15,20,25$ and $30 \mathrm{wt} \%$ to $100 \mathrm{wt} \%$ of the matrix. Weight percentages were chosen with a respect to a practical application when the filler is mixed mainly on the basis of weight ratios.

The adhesive bond strength was determined using the single-lap shear test according to CSN EN 1465. Laboratory tests were performed using the standardized test specimens made according to the standard CSN EN 1465 (dimensions $100 \pm$ $0.25 \times 25 \pm 0.25 \times 1.5 \pm 0.1 \mathrm{~mm}$ and lapped length of $12.5 \pm 0.25 \mathrm{~mm}$ ) from the carbon steel S235J0.

A surface treatment is essential not only in the area of the adhesive bonding technology $[14,21$, 25-33]. The surface of the carbon steel S235J0 determined for the bonding was mechanically and chemically treated. The mechanical treatment consisted in a grit blasting of the bonded area by the Garnet MESH 80. The chemical cleaning consisted in removing impurities in a bath of Acetone. Roughness parameters $\mathrm{Ra}$ and $\mathrm{Rz}$ were measured on the surface of bonded adherents. Roughness parameters were measured with a portable profilometer Mitutoyo Surftest 301. A limit wavelength of the cut-off was set as $0.8 \mathrm{~mm}$.

The adhesive was evenly applied on one bonded surface. The adhesive bonds were fixed with a weight of $750 \mathrm{~g}$ after applying second bonded part. The lapping was according to the standard CSN EN $146512.5 \pm 0.25 \mathrm{~mm}$. Adhesive bonds were cured for $72 \pm 5$ hours with a temperature 22 $\pm 2^{\circ} \mathrm{C}$. The reason was reaching the full strength of the adhesive bond and a minimization of the influence of the secondary hardening.

Laboratory tests were performed using the universal tensile strength testing machine LABTest 5.50ST (a sensing unit AST type KAF $50 \mathrm{kN}$, an evaluating software Test\&Motion). The 
loading speed of the deformation corresponded to $5 \mathrm{~mm} / \mathrm{min}$. The failure type according to ISO 10365 was determined at the adhesive bonds.

Fracture surfaces and an adhesive bond cut was examined with SEM (scanning electron microscopy) using a microscope MIRA 3 TESCAN (the fracture surfaces were dusted with gold) at the accelerating voltage of the pack (HV) $5.0 \mathrm{kV}$ and a stereoscopic microscope Arsenal. An evaluation of the shape and the dimension was performed using the program Gwiddion. The results of measuring were statistically analysed. Statistical hypotheses were also tested at measured sets of data by means of the program STATISTICA. A validity of the zero hypothesis $\left(\mathrm{H}_{0}\right)$ shows that there is no statistically significant difference ( $p>$ 0.05 ) among tested sets of data. On the contrary, the hypothesis $\mathrm{H}_{1}$ denies the zero hypothesis and it says that there is a statistically significant difference among tested sets of data or a dependence among variables $(\mathrm{p}<0.05)$. For the correct evaluation it is also important to determine the determination index $\mathrm{R}^{2}$. It is the problem of the correlation analysis. The values of the determination index can be from 0 to 1 . So far as $\mathrm{R}^{2}$ equals to 1 , there is a perfect correlation in this sample (so there is no difference between a calculation and real values).

\section{RESULTS AND DISCUSSION}

The considered particle sizes reached $14.46 \pm$ $7.42 \mu \mathrm{m}$ (aluminium length), $2.02 \pm 0.82 \mu \mathrm{m}$ (aluminium width) and $42.57 \pm 25.11 \mu \mathrm{m}$ (polymer spherical particles). The surface roughness of the adhesive bonded material (structural carbon steel S235J0) was in in the direction perpendicular to the loading force at the destructive testing of the adhesive bonds Ra $1.99 \pm 0.15 \mu \mathrm{m}, \mathrm{Rz} 11.70 \pm$ $0.83 \mu \mathrm{m}$.

The adhesive layer thickness was measured as $173.14 \pm 12.42 \mu \mathrm{m}$. The optimum shear strength was reached at the two-component structural epoxy adhesives in the interval of the adhesive layer thickness 0.1 to $0.25 \mathrm{~mm}[2,4]$.

Figures 1 and 2 show a histogram of a frequency of aluminium microparticles. It is obvious from the results that the highest portion was at the aluminium microparticles among 10 to 15 $\mu \mathrm{m}$ (a length) and 1.5 to $2.0 \mu \mathrm{m}$ (a width). Figure 3 shows a histogram of a frequency of a polymer filler. It is obvious from the results that the highest

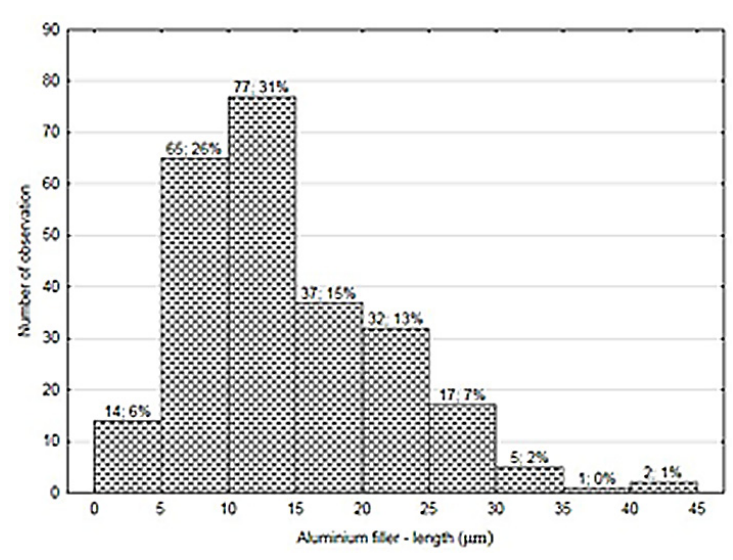

Fig. 1. Histogram of length of filler in form of aluminium microparticles

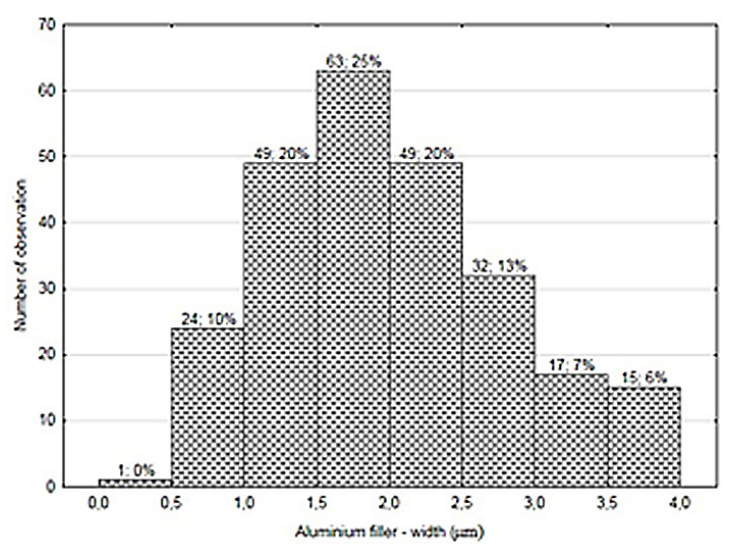

Fig. 2. Histogram of width of filler in form of aluminium microparticles

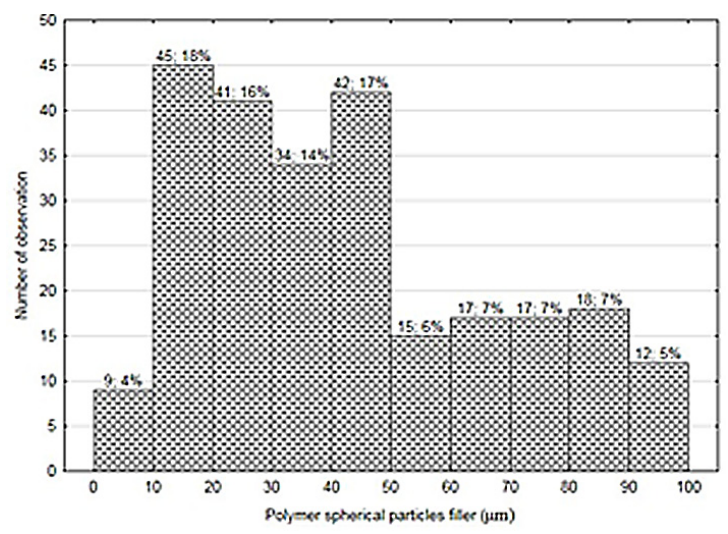

Fig. 3. Histogram of mean of filler in form of polymer spherical microparticles

portion was at the spherical polymer microparticles among 10 to $50 \mu \mathrm{m}$. The polymer filler was of very different dimensions. It is obvious from the adhesive bond strength results that adding the filler changes the adhesive bond strength and elongation (Fig. 4). The highest adhesive bond strength increase was at the adhesive bond with 


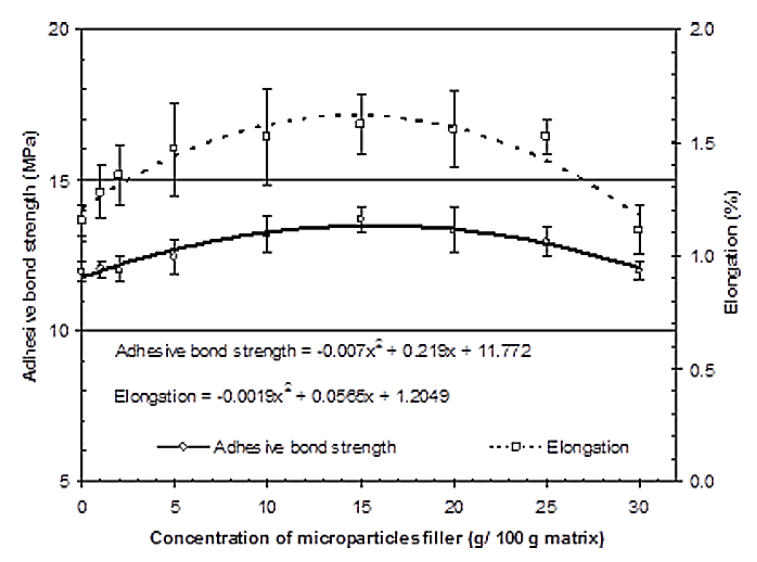

Fig. 4. Influence of filler concentration on adhesive bond strength and on elongation (adherent - structural carbon steel S235J0)

the adhesive in the form of the composite ( $15 \mathrm{~g}$ of the filler : $100 \mathrm{~g}$ of the matrix). The adhesive bond strength increase was $14.3 \%$.

The Elongation also changed when adding the filler. It was increased. The highest elongation was at the adhesive bond with the adhesive in the form of the composite ( $15 \mathrm{~g}$ of the filler : $100 \mathrm{~g}$ of the matrix). The elongation increase was $36.9 \%$.

It is possible to say in terms of the statistical testing (T-test, $\alpha=0.05$ ) of the influence of various filler concentrations on the adhesive bond strength and the elongation that concentrations are statistically non-homogeneous groups. The hypothesis $\mathrm{H}_{0}$ was not certified i.e. there is a difference in the adhesive bond strength and the elongation in 0.05 significance level among single tested materials, i.e. the matrix and various concentrations of the filler (adhesive bond strength $p=0.00$, elongation $\mathrm{p}=0.00$ ). The statistical testing confirmed that there is a huge difference in observed mechanical properties among tested concentrations.

The polynomial second order function presented in fig. 4 reaches a strong dependence of the adhesive bond strength $\left(\mathrm{R}^{2}=0.953\right)$ and elongation $\left(\mathrm{R}^{2}=0.899\right)$ on the filler. A trend of the increase and subsequently the decrease of the adhesive bond strength and the elongation was possible to describe by a polynomial second order function presented in fig. 4 ( $\mathrm{x}-\mathrm{a}$ concentration of microparticles filler).

The bonds adhesive bonded with the structural two-component adhesive showed an adhesive failure type. The bonds adhesive bonded with the composite adhesive filled with the aluminium and polymer showed an adhesive-cohesive and a cohesive failure type of the adhesive bond (fig. 5). So, adding the filler changed the type of the fracture surface. There was difference between the adhesive bonds without the filler (the matrix) and with the filler. A good interaction of the filler in the form of the aluminium powder and polymer microparticles with the matrix in the form of the epoxy was proved using the electron microscopy (Fig. 5) within the experimental research. The residues of the matrix are visible on the surface of the polymer filler. A good wettability of this filler follows from that. It came to the increase of the adhesive bond strength. The adhesion of the adhesive was increased owing to adding the aluminium and polymer microparticles. The presence of diversely large filler particles was proved using the electron microscopy within the experimental research (Fig. 5). The aluminium microparticles were of the multi-plate shape. The plastics microparticles were of the spherical shape. The research results proved a good wettability between the adhesive and the filler. A strong interaction between adhesive and particles is evident (Fig. 5). A presence of cracks in the boundary adherent / adhesive was proved using the electron microscopy within the experimental research (Fig. 6). The adhesive/cohesive failure of the adhesive bonds originated also in these cracks.

From the results of the experiment it is possible to agree with the statement that epoxy adhe-

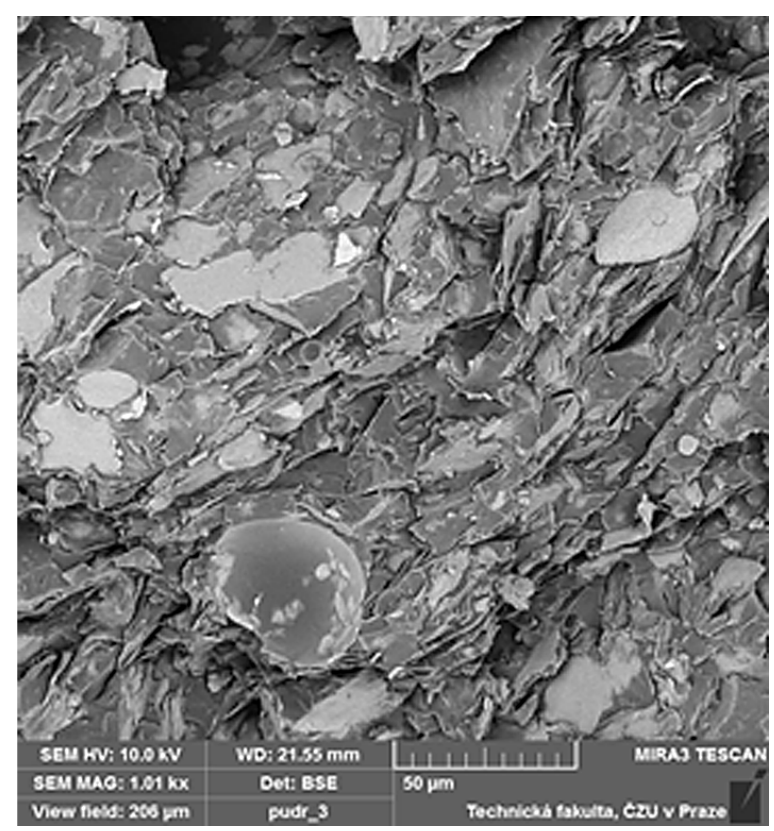

Fig. 5. SEM images of composite material - Cohesive fracture surface of adhesive bond bonded with composite adhesive (microparticles of aluminium (multi-plate shape) and polymer particles (spherical shape), perfect wetting of filler with resin) 


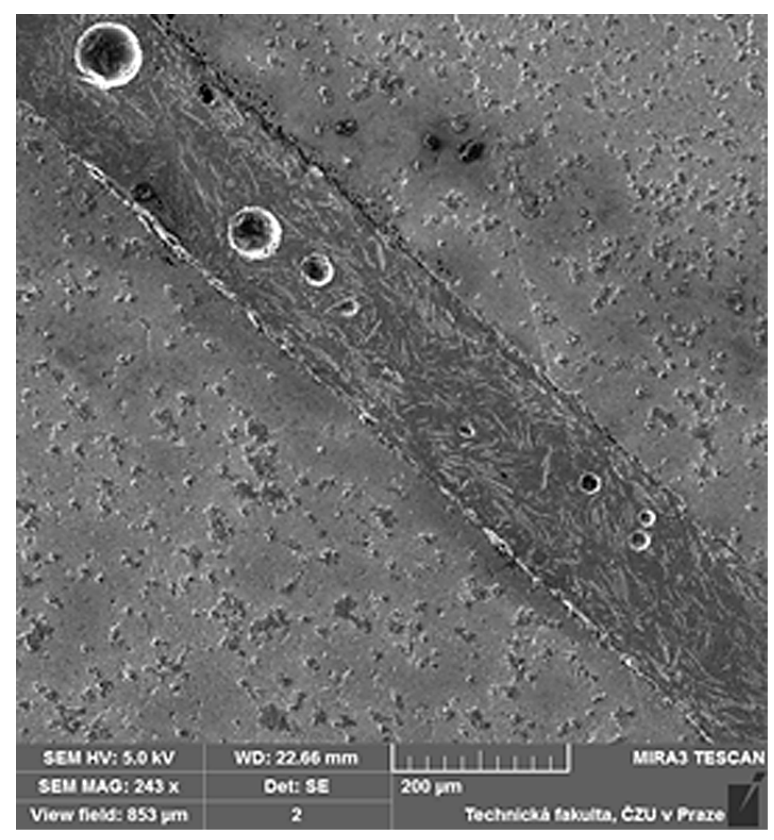

Fig. 6. SEM images of microcracks in boundary adherent S235J0 / adhesive

sives preserve their adhesive bond strength also at high concentrations of the filler [13].

A strong interaction between adhesive and particles is evident. When applying the filler into the resin, the wetting of the filler with the matrix is very important [23]. Results of the experiment also show the irregular stratification of filler microparticles in the matrix (Fig. 5). Chang et al. (2001) proved in their experiments that the irregular shape of the particles ensured good interaction between the matrix and the filler. The assumption about a negative influence of the filler on the tensile strength was not confirmed. Cho et al. [16] state that there is a decrease in the strength of the composite with increasing volume of filler particles.

Results of the experiments confirmed conclusions of Ramazan et al. [13], where they state that there was a slight increase of the adhesive bond strength of testing samples with adding the aluminium microparticles.

By adding the filler in the form of aluminium and polymer microparticles there was a change in a failure type. Therefore it is possible to agree with the statement of Ramazan et al. [13] that filled epoxy resin improved the adhesion to the bonded surface.

From the results of the experiment it is possible to agree with the statement, that epoxy adhesives preserve their adhesive bond strength also at high concentrations of the filler [13]. A strong interaction between due adhesive and particles is evident from Figure 6.
The assumption about a negative influence of the filler on the adhesive bond strength was not confirmed. It is possible to agree with the statement that inorganic fillers improve mechanical properties of the polymer [34]. The adhesive bond in this case.

\section{CONCLUSIONS}

Particle composites are used, above all, in applications where we cannot specify the stress in advance or the stress is approximately the same in all directions. Further, the particle composites are applied in situations where the requirements for easy workability and good mechanical properties are.

Following conclusions can be deduced from the results of the experiment focused on the research on the influence of the filler concentrations in the form of the aluminium microparticles and polymer on the mechanical properties of the polymeric particle composite and adhesive bonds of the material structural carbon steel S235J0:

1. The adhesive bond strength and the elongation changed when adding the filler. The adhesive bond strength increased when adding the filler. The highest increase of the adhesive bond strength was at the adhesive bond with the adhesive in the form of the composite (15 $\mathrm{g}$ of the filler : $100 \mathrm{~g}$ of the matrix). The increase of the adhesive bond strength was $14.3 \%$. The elongation showed a similar behaviour.

2. The adhesive bonds (matrix - structural twocomponent adhesive) evinced an adhesive type of the fracture surface. The failure type was changed when adding the filler in the form of the microparticles.

\section{Acknowledgements}

Supported by Internal grant agency of Faculty of Engineering, Czech University of Life Sciences Prague (Research on mechanical properties of multi-component polymer systems during their preparation, processing and application, 2016:31140/1312/3109).

\section{REFERENCES}

1. Müller M., Herák D., Valášek, P.: Degradation limits of bonding technology depending on destina- 
tions Europe, Indonesia. Tehnicki Vjesnik-Technical Gazette, 20(4), 2013, 571-575.

2. Müller M., Chotěborský R., Valášek P., Hloch S.: Unusual possibility of wear resistance increase research in the sphere of soil cultivation. Tehnicki Vjesnik-Technical Gazette, 20(4), 2013, 641-646.

3. Müller M., Valášek P.: Degradation medium of agrokomplex - adhesive bonded joints interaction. Research in Agricultural Engineering, 58, 2012, 83-91.

4. Müller M.: Influence of cyclic degradation in saline solution on mechanical properties of adhesive bonds. Manufacturing Technology, 16(1), 2016, 204-209.

5. Borsellino C., Bell G., Di Ruisi V.F.: Adhesive joining of aluminium AA6082: The effects of resin and surface treatment. International Journal of Adhesion and Adhesives, 29, 2009, 36-44.

6. Müller M.: Research of liquid contaminants influence on adhesive bond strength applied in agricultural machine construction. Agronomy Research, 11(1), 2013, 147-154.

7. Rudawska A.: Influence of the thickness of joined elements on lap length of aluminium alloy sheet bonded joints. Advances in Science and Technology Research Journal, 9(27), 2015, 35-44.

8. Valášek P., Müller, M.: Abrasive wear in threephase waste based polymeric particle composites. Tehnicki Vjesnik-Technical Gazette, 12(2), 2015, 257-262.

9. Valášek P., Müller M., Hloch S.: Recycling of corundum particles - two-body abrasive wear of polymeric composites based on waste. Tehnicki Vjesnik-Technical Gazette, 22(3), 2015, 567-572.

10. Rudawska A.: Pressure during curing and the strength of 2024, 2017A and 1050 aluminium alloy sheet adhesive joints. Advances in Science and Technology Research Journal, 9(26), 2015, 96-103.

11. Rudawska A., Czarnota M.: Selected aspects of epoxy adhesive compositions curing process. Journal Adhesion Science and Technology, 27(17), 2013, 1933-1950.

12. Rudawska A.: Surface free energy and geometric structures of the surfaces of selected epoxy composites. Polimery, 53, 2008, 452-456.

13. Ramazan K., Mehmet S., Bekir Y.: Influence of adhesive thickness and filler content on the mechanical performance of aluminium single-lap joints bonded with aluminium powder filled epoxy adhesive. Journal of Materials Processing Technology, 205, 2008, 183-189.

14. Rudawska A.: Surface Free Energy and 7075 Aluminium Bonded Joint Strength Following Degreasing Only and Without Any Prior Treatment. Journal Adhesion Science and Technology, 26, 2012,
1233-1247.

15. Rudawska A.: Selected aspects of the effect of mechanical treatment on surface roughness and adhesive joint strength of steel sheets. International Jurnal of Adhesion and Adhesives, 50, 2014, 235-243.

16. Cho J., Joshi M.S., Sun C.T.: Effect of inclusion size on mechanical properties of polymeric composites with micro and nano particles. Composites Science and Technology, 66, 2006, 1941-1952.

17. Shao-Yun Fu, Xi-Qiao Feng, Bernd Luke, YiuWing Mai: Effects of particle size, particle/matrix interface adhesion and particle loading on mechanical properties of particulate-polymer composites. Composites: Part B, 39, 2008, 933-961.

18. Müller M.: Polymer composites based on AL2O3 reinforcing particles. Engineering for Rural Development 26.05.2011, Jelgava. Jelgava: Latvia University of Agriculture, 2011, 423-427.

19. Müller M., Cidlina J., Dědičová K., Krofová K.: Mechanical properties of polymer composite based on aluminium microparticles. Manufacturing Technology, 15(4), 2015, 624-628.

20. Müller M.: Research of liquid contaminants influence on adhesive bond strength applied in agricultural machine construction. Agronomy Research, 11(1), 2013, 147-154.

21. Ruggiero A., Valášek P., Merola M.: Friction and wear behaviors of $\mathrm{Al} /$ Epoxy composites during reciprocating sliding tests. Manufacturing Technology, 15(4), 2015, 684-689.

22. Valášek P., Müller M.: Aplikace otěruvzdorných polymerích částicových kompozitů v oblasti konstrukce orebního tělesa. Listy Cukrovarnické a Řepařské, 130(9-10), 2014, 284-288.

23. Jäckel M., Scheibner W.: Boundary layer induced modification of thermal and mechanical properties of epoxy resin composites Boundary layer induced modification of thermal and mechanical properties of epoxy resin composites. Cryogenics, 31(4), 1991, 269-272.

24. Józwik J., Kuric I., Sága M., Lonkowic P.: Diagnostics of $\mathrm{CNC}$ machine tools in manufacturing process with laser interferometer technology. Manufacturing Technology, 14, 2014, 23-30.

25. Kováč I., Mikuš R., Žarnovský J., Drlička R., Žitňaský J., Výrostková A.: Creation of wear resistant boride layers on selected steel grades in electrical arc remelting process. Kovové Materially. 52, 2014, 387-397.

26. Novák M.: Surfaces with high precision of roughness after grinding. Manufacturing Technology, 12, 2012, 66-70.

27. Ruggiero A., D’Amato R., Gómez E., Merola M.: Experimental comparison on tribological pairs UHMWPE/TIAL6V4 alloy, UHMWPE/AISI316L 
austenitic stainless and UHMWPE/AL2O3 ceramic, under dry and lubricated conditions. Tribology International, 96, 2016, 349-360.

28. Ruggiero A., Merola M., Carlone P., Archodoulaki V.: Tribo-mechanical characterization of reinforced epoxy resin under dry and lubricated contact conditions. Compos Part B: Eng., 79, 2015, 595-603.

29. Ruggiero A., Hloch S., Kozak D., Valasek P.: Analytical fluid film force calculation in the case of short bearing with a fully developed turbulent flow. In. Proceedings of the Institution of Mechanical Engineers, Part J: Journal of Engineering Tribology, 230(4), 2016, 395-401.

30. Sadílek M., Kratochvíl J., Petrů J, Cep R., Zlámal T., Stančeková D.: Cutting tool wear monitoring with the use of impedance layers. Tehnicki Vjesnik, 21(3), 2014, 639-644.
31. Náprstková N., Cais J., Stančeková D.: Influence of $\mathrm{AlSi} 7 \mathrm{Mg} 0.3$ alloy modification by $\mathrm{Sb}$ on the tool wear. In. Manufacturing Technology, 1, 2014, 75-79.

32. Stančekova D., Kurnava T., Sajgalik M., Náprstková N., Struharnansky J., Ščotka P.: Identification of machinability of ceramic materials by turning. Manufacturing Technology, 1, 2014, 91-97.

33. Mrazova M., Stancekova D., Semcer J.: Comparasion of machinability of biocompatible materials used in medicine for dental implants. In: DAAAM and Proceedings of the International DAAAM Symposium, 2011, 1115-1116.

34. Farrah N.A., Mariatti J., Samayamuthirian P., Khairun A.M.: Effect of particle shape of silica minerál on the properties of epoxy composites. Composites Science and Technology, 68, 2008, 346-353. 